\title{
MODIFIKASI GIGI MANUSIA BINANGUN DAN LERAN: "Temuan Baru di kawasan Pantai Utara Kabupaten Rembang, Jawa Tengah"
}

\section{HUMAN TEETH MODIFICATION IN BINANGUN AND LERAN: "New findings in the Northern Coast of Rembang District, Central Java"}

\author{
Gunadi Kasnowihardjo ${ }^{1}$, Rusyad Adi Suriyanto ${ }^{2}$, Toetik Koesbardiati ${ }^{3}$ \& Delta Bayu Murti ${ }^{4}$ \\ ${ }^{1}$ Balai Arkeologi Yogyakarta \\ ${ }^{2}$ Laboratorium Bioantropologi dan Paleoantropologi, Fakultas Kedokteran, Universitas Gadjah Mada. \\ ${ }^{3,4}$ Jurusan Antropologi, Fakultas IImu Sosial dan IImu Politik, Universitas Airlangga \\ gunbalar@yahoo.com
}

\begin{abstract}
Something interesting about the findings of the human skeleton in Binangun and Leran Prehistoric Burial Sites is the modification of the human teeth that is extremely rare found in prehistoric grave in Java as well as in Indonesia. Such tradition is still practiced in Java and Bali by leveling the top or bottom front teeth (Jawa: pangur tradition). Forms of human teeth of Binangun, Leran 1 and Leran 2 are very unique, teeth of Binangun is tapered while human teeth of Leran 1 and Leran 2 shaped like a flower bud. Anatomically the shape of teeth can be altered by a person in the habit of using his teeth. But variations in tooth shape as found in individuals in the Binangun and Leran sites, Rembang regency, Central Java province, in general is the result of a tribal culture.
\end{abstract}

Keywords : Prehistoric Sites, Teeth Modification, Prehistoric Culture.

\section{ABSTRAK}

Satu hal yang menarik dari temuan rangka manusia di Situs Binangun dan Situs Leran adalah ditemukannya modifikasi gigi-geligi yang sangat jarang ditemukan di situs-situs kubur prasejarah baik di Jawa maupun di Indonesia. Di Jawa dan Bali, tradisi modifikasi gigi manusia pada umumnya gigi bagian depan atas maupun bawah dibentuk merata (tradisi pangur gigi). Bentuk gigi manusia Binangun dan manusia Leran 1 dan Leran 2 sangat unik, gigi manusia Binangun bentuknya meruncing, sedangkan gigi manusia Leran 1 dan Leran 2 berbentuk mirip kuncup bunga. Secara anatomis bentuk gigi dapat mengalami perubahan akibat kebiasaan seseorang dalam menggunakan giginya. Akan tetapi bentuk gigi yang bervariasi seperti yang ditemukan pada individu di Situs Binangun dan Situs Leran, Kabupaten Rembang, Jawa Tengah pada umumnya merupakan hasil dari budaya suatu suku bangsa.

Kata kunci: Situs Prasejarah, Modifikasi Gigi, Budaya Prasejarah.

Tanggal masuk : 16 September 2013

Tanggal diterima : 24 November 2013 


\section{PENDAHULUAN}

Akhir-akhir ini perhatian para peneliti arkeologi prasejarah Indonesia beberapa di antaranya disemangati oleh diaspora bangsa-bangsa penutur rumpun bahasa Austronesia. Sebagai rumpun bahasa, Austronesia merupakan rumpun bahasa yang terbesar dan tersebar di dunia. Masyarakat penuturnya menempati hampir sepertiga belahan bumi yaitu dari TaiwanMikronesia di utara hingga New Zealand di selatan dan dari Madagaskar di barat hingga Easter Island di timur (Masinambow, dkk 2004). Salah satu teori tentang sebaran masyarakat penutur rumpun bahasa Austronesia yang sampai saat ini banyak diikuti oleh para ahli adalah Teori Out of Taiwan yang dicetuskan oleh Peter Bellwood. Dijelaskan oleh Bellwood bahwa selama akhir milenium kelima atau keempat Sebelum Masehi (SM), para kolonis dari daratan Cina selatan (Zhejiang atau Fujian) menduduki Pulau Taiwan. Bahasabahasa Austronesia ${ }^{1}$ awal dipakai di pulau ini selama beberapa abad (satu milenium?) sebelum sebagian dari mereka melanjutkan ekspansi ke pulau-pulau berikutnya. Selama milenium ketiga SM para kolonis telah mengokupasi Pulau Luzon, di sinilah berkembang subkelompok bahasa Melayu-Polinesia yang mulai memisahkan diri dari subkelompok Austronesia yang tetap tinggal di Taiwan. Demikian seterusnya perjalanan kolonis penutur rumpun bahasa Austronesia hingga akhirnya mereka mencapai Asia Tenggara. Dari sinilah perjalanan diteruskan ke selatan sampai New Zealand, ke timur hingga Pulau Paskah dan ke barat sampai Madagaskar (Bellwood 2000, 352-355).

\footnotetext{
Austronesia adalah sebutan untuk rumpun bahasa yang berasal dari bahasa Austrik yaitu bahasa yang digunakan di daerah Yunan, Tiongkok. Bahasa ini kemudian pecah menjadi dua yaitu rumpun bahasa Austro-Asiatik seperti yang digunakan oleh orang-orang Mong-Khmer dan Suku Munda; dan rumpun bahasa Austronesia yang digunakan oleh masyarakat yang mendiami pulau-pulau yang tersebar di Asia Tenggara dan Pasifik.
}

Di Indonesia masyarakat penutur bahasa Austronesia memiliki peran penting dalam kaitannya dengan sejarah kebudayaan Indonesia. Bukti-bukti tinggalan artefaktual ditemukan tersebar hampir di seluruh kepulauan Indonesia. Masyarakat Austronesia yang identik dengan masyarakat petani peralatan yang paling menonjol pada saat itu adalah beliung persegi. Soejono (1992) menyatakan bahwa alat batu tersebut banyak tersebar di Indonesia, di Sumatra antara lain ditemukan di Bengkulu, Palembang dan Lampung. Di Jawa temuan beliung persegi cukup merata yaitu di Banten, Bogor, Cibadak, Bandung, Tasikmalaya, Cirebon, Pekalongan, Banyumas, Semarang, Kedu, Yogyakarta, Wonogiri, Punung, Surabaya, Madura, Malang, dan Besuki. Selanjutnya beliung persegi juga ditemukan di Kalimantan, Sulawesi, Bali, Solor, Adonara, Ternate, Maluku, Sangihe-Talaud (Heekeren 1972, 168-178). Selain Beliung Persegi kadangkadang di situs yang sama ditemukan pula sisa-sisa perkakas gerabah yang juga menjadi ciri masyarakat Austronesia. Temuan artefak tersebut sangat sedikit yang didukung data tentang manusia pemakai perkakas tersebut, oleh karena itu penelitian dengan sasaran mencari manusia pendukung atau penutur rumpun bahasa Austronesia perlu lebih ditingkatkan.

Di Plawangan, Kecamatan Kragan, Kabupaten Rembang, Jawa Tengah pernah ditemukan Situs Kubur Prasejarah yang oleh Haris Sukendar dan Rokhus Due Awe (1981) diklasifikasikan dalam masa paleometalik. Hasil laporan penelitian Situs Plawangan yang diterbitkan dalam Berita Penelitian Arkeologi No. 27 oleh Proyek Penelitian Purbakala Jakarta, Departemen P \& K tidak menjelaskan lebih jauh tentang temuan rangka baik yang berasal dari kubur primer maupun kubur sekunder. Santoso Soegondho (1995) menjelaskan hubungan yang erat antara benda-benda gerabah, manik-manik, benda logam, dan keramik Cina dengan rangka manusia 
dalam sistem penguburan ${ }^{2}$. Benda-benda itu kebanyakan menjadi alat perlengkapan penguburan atau sering disebut sebagai bekal kubur (Soegondho 1995, 25-27). Pada tahun 1980-an Bapak Slamet Widjaja, Penilik Kebudayaan Kecamatan Lasem, Kabupaten Rembang pernah menemukan beliung persegi di wilayah Desa Bonang, Kecamatan Lasem. Berdasarkan dua hal di atas, maka diperkirakan di sepanjang pantai utara antara Plawangan dan Bonang kemungkinan memiliki situs-situs kubur seperti yang ditemukan di Plawangan. Untuk itu, maka penelitian mencari manusia pendukung budaya Austronesia dilakukan di sepanjang pantai antara Plawangan dan Bonang. Ternyata dugaan itu tidak meleset karena tim penelitian menemukan situs kubur prasejarah di Pantai Leran dan Pantai Binangun (Gunadi, dkk. 2012; 2013).

Kajian historis arkeologis hasil penelitian Situs Kubur Prasejarah di Pantai Utara Kabupaten Rembang, Jawa Tengah telah dibahas oleh Kasnowihardjo dalam satu artikel pada Jurnal Berkala Arkeologi Vol. 33 No. 1 edisi bulan Mei 2013 berjudul "Pendukung Budaya Austronesia Di Pantura Jawa Tengah, Sebuah Kajian Awal". Beberapa tengkorak rangka manusia yang ditemukan di Situs Leran dan Binangun keempat gigi seri dari rahang atas memiliki bentuk gigi yang aneh. Berdasarkan pengamatan Toetik Koesbardiati, gigi seri tengkorak Binangun berbentuk meruncing mirip dengan gigi gergaji, sedangkan tengkorak Leran gigi seri bagian atas berbentuk mirip kuncup bunga (Gunadi, dkk. 2012). Temuan tengkorak dan rangka manusia dengan bentuk gigi-geligi seperti tersebut menarik untuk dilakukan kajian dan penelitian lebih lanjut. Mengingat bentuk gigi seperti disebutkan di atas sengaja dibentuk atau terbentuk secara alami akibat kebiasaan dalam menggunakan gigi, belum banyak

\footnotetext{
Sistem penguburan masa prasejarah lebih lanjut dapat dibaca disertasi Prof. R.P. Soejono berjudul "Sistem-Sistem Penguburan Pada Akhir Masa Prasejarah di Bali”.
}

dilakukan dalam kajian arkeologi di Indonesia. Sementara di negara-negara maju penelitian tentang gigi-geligi manusia tidak lagi sebatas fungsi sebagai alat pengunyahan, berbicara, dan estetika (penampilan) akan tetapi telah berkembang ke dalam kajian antropologis yaitu dengan menambahkan fungsi gigi sebagai artefak yang dapat menjelaskan tentang perilaku manusia (Milner \& Larsen 1991).

\section{METODE PENELITIAN}

Di dalam kelompok ilmu Humaniora, ekskavasi atau penggalian adalah metode yang hanya dimiliki oleh disiplin arkeologi sebagai sarana dalam mencari dan mengumpulkan data. Termasuk di dalamnya adalah kegiatan penggambaran dan pemetaan (periksa lampiran 2 dan 3 ). Selain ekskavasi, dalam penelitian arkeologi pengumpulan data juga dilakukan melalui survei baik data artefaktual maupun non-artefaktual yang dilakukan dengan wawancara. Dari studi literatur akan diperoleh berbagai informasi terkait dengan tema yang sedang diteliti. Sintesa antara data yang diperoleh dari hasil penelitian dan bukti-bukti serta data sejenis dari situs lain, merupakan hasil akhir dari penelitian ini. Hasil penelitian ini bersifat hipotetik yang sangat terbuka untuk dilakukan pengujian kembali oleh siapapun. Penelitian "bio-arkeologi" ${ }^{3}$ ini merupakan kolaborasi antara arkeologi dan paleoantropologi. Metode penelitian seperti ini di Indonesia bukan sesuatu yang baru, karena sejak tahun 1975-an Prof. T. Jacob $\mathrm{MD}^{4}$ dan Prof. R.P.

\footnotetext{
Berasal dari Bioarchaeolog, dicetuskan pertama kali oleh Grahame Clark pada tahun 1972 dalam rangka mengakomodasi penelitian tulang-belulang binatang dan manusia di situs arkeologi. Adapula yang mengistilahkan Osteoarchaeology (International Journal of Osteoarchaeology).

4 Seorang dokter umum yang menekuni bidang paleoantropologi. Beliau selama beberapa dasawarsa merupakan satu-satunya ahli paleoantropologi di Indonesia. Pernah menjabat sebagai Rektor Universitas Gadjah Mada, Yogyakarta.
} 
Soejono ${ }^{5}$ sering melakukan penelitian bersama terutama penelitian di situs-situs manusia purba seperti di Sangiran dan tempat lain baik di Jawa maupun di luar Jawa.

Memperhatikan contoh seperti telah dilakukan oleh para peneliti senior di atas, maka dalam penelitian Situs Kubur Prasejarah di Leran dan Binangun metode yang diterapkan dilakukan secara kolaboratif dengan melibatkan berbagai disiplin seperti Arkeologi, Paleoantropologi, dan Geologi. Sedangkan teknik pengumpulan data antara ekskavasi dan survei dilakukan secara simultan dalam waktu yang bersamaan. Khusus bagi para peneliti dari disiplin paleoantropologi, mereka melakukan kegiatan analisis setelah ditemukan data rangka manusia. Sehingga mereka tidak perlu berada di lapangan sejak awal hingga akhir waktu penelitian. Tim penelitian kali ini terdiri dari peneliti Balai Arkeologi Yogyakarta, Jurusan Arkeologi, Fakultas IImu Budaya, Universitas Gadjah Mada, Ahli Paleoantropologi dari Universitas Airlangga, dan Ahli Geologi dari Universitas Gadjah Mada.

\section{GIGI-GELIGI MANUSIA BINANGUN DAN MANUSIA LERAN}

Situs Binangun terletak di sebuah tanjung pantai Binangun, Desa Binangun, Kecamatan Lasem, Kabupaten Rembang, Jawa Tengah, dikenal sejak ditemukannya sepotong tulang panjang yang muncul di tebing pantai oleh seorang warga setempat pada tahun 2010. Berita penemuan tersebut sempat mengundang perhatian masyarakat dan aparat pemerintah setempat. Bahkan oleh Kepolisian Sektor Lasem langsung menempatkan police line di lokasi penemuan tersebut. Hal ini dilakukan karena kecurigaan Polisi atas temuan

\footnotetext{
5 Bapak Prasejarah Indonesia dan ahli prasejarah pertama di Indonesia, menjabat sebagai Kepala Pusat Penelitian Arkeologi Nasional paling lama dan sampai akhir hayat waktunya didedikasikan untuk arkeologi Indonesia.
}

potongan tulang manusia itu diperkirakan akibat dari pembunuhan yang terjadi beberapa waktu lalu. Pada tahun berikutnya 2011 Dr. Toetik Koesbardiati dari Universitas Airlangga dan Rusyad Adisuriyanto dari Laboratorium BioPaleoantropologi, Universitas Gadjah Mada meninjau situs Binangun untuk memastikan adanya temuan rangka manusia di situs tersebut. Pada saat itu pula tengkorak manusia Binangun diamankan dan dititipkan di Museum Plawangan ${ }^{6}$, karena pertimbangan pelestarian atas temuan yang diduga sebagai bagian dari rangka manusia prasejarah dan termasuk dalam kategori benda cagar budaya.

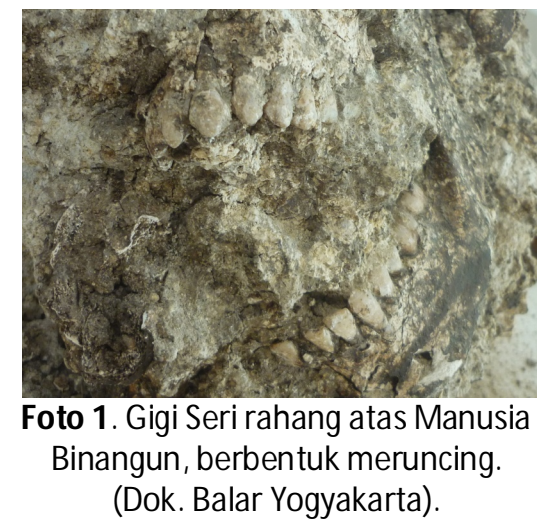

Pada tahun 2012 Balai Arkeologi Yogyakarta berkesempatan merespon atas berita penemuan Situs Binangun, yaitu dengan melakukan penelitian yang melibatkan berbagai pihak seperti Bidang Paleoantropologi Universitas Airlangga, Surabaya dan Jurusan Arkeologi Universitas Gadjah Mada, Yogyakarta. Selain melakukan kegiatan ekskavasi dan survey sebagian peneliti ke Museum Plawangan untuk mengamati dan membersihkan tengkorak manusia Binangun yang masih terbungkus tanah. Dari hasil pembersihan diketahui bahwa 4

\footnotetext{
6 Sebutan masyarakat untuk sebuah bangunan milik Pusat Penelitian Arkeologi Nasional yang terletak di Desa Plawangan, Kecamatan Kragan, Kabupaten Rembang. Bangunan ini berfungsi sebaga' rumah artefak dan tidak dapat disebut sebagai museum karena tidak ada artefak yang dipamerkan layaknya sebua'ı museum.
} 
(empat) buah gigi seri bagian atas manusia Binangun memiliki bentuk yang berbeda dengan gigi lainnya karena meruncing mirip mata gergaji (periksa foto 1).

Kondisi tengkorak dan rangka manusia Binangun saat ditemukan sudah tidak utuh dan seluruh rongga tengkorak terpenuhi material tanah yang telah mengeras dan menyatu dengan tulang belulang sehingga cukup sulit untuk dibersihkan. Dari foto di atas dapat diketahui bahwa rangka manusia Binangun pernah mengalami suatu peristiwa alam(?) yang menyebabkan antara rahang atas dan rahang bawah terbuka sangat lebar, akibatnya seluruh rongga mulut terpenuhi material dari batuan di sekelilingnya. Akan tetapi untuk mengetahui hal tersebut selain perlu kajian geologis juga perlu penelitian lanjutan untuk mencari data yang sejenis dan sejaman sebagai bahan perbandingan. Hal itu dimungkinkan karena di area Situs Binangun terdapat beberapa titik yang diperkirakan mengandung jenis rangka yang sama dengan manusia Binangun.

Bentuk gigi-geligi lain ditemukan pula di Situs Leran yang terletak kira-kira satu kilometer di sebelah timur Situs Binangun. Kondisi Situs Leran saat ditemukan oleh Tim Penelitian Balai Arkeologi Yogyakarta sangat mengkhawatirkan karena terancam bencana abrasi air laut yang sangat kuat. Oleh karena abrasi beberapa tulang belulang dan tengkorak Manusia Leran tampak pada dinding pantai yang tergerus ombak Laut Jawa. Beberapa tengkorak dan bagian rangka manusia Leran berhasil diangkat dan dibawa ke Balai Arkeologi Yogyakarta untuk dilakukan analisis dan penanganan ataupun perlakukan selanjutnya. Selain itu, adapula rangka manusia lengkap dengan tengkoraknya yang sengaja tidak diangkat dari lubang penggalian. Setelah dilakukan pendokumentasian dan pencatatan secara lengkap salah satu rangka manusia Leran dikubur kembali dengan terlebih dahulu

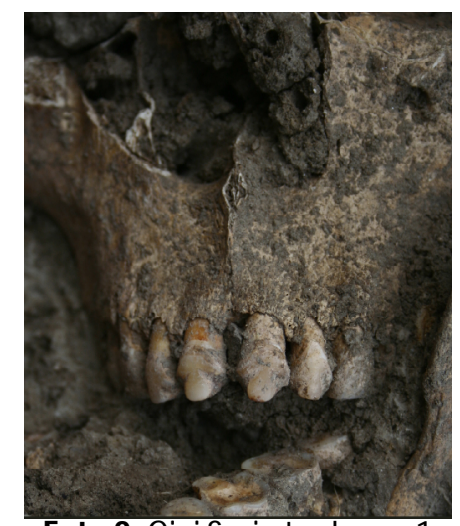

Foto 2. Gigi Seri atas Leran 1

(Dok. Balar Yogyakarta)

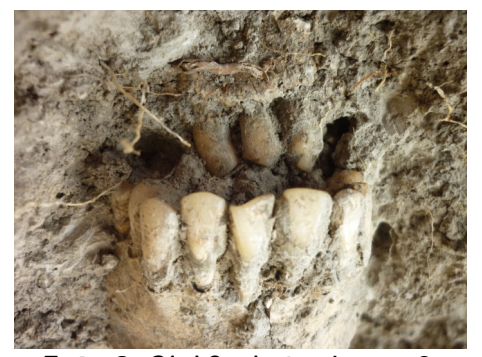

Foto 3. Gigi Seri atas Leran 2 (Dok. Balar Yogyakarta)

menutup kotak penggalian dengan papan kayu agar tidak langsung tertimbun tanah.

Berbeda dengan gigi manusia Binangun, yang berdasarkan analisis awal Toetik Koesbardiati menyatakan bahwa gigi manusia Leran 1 dan Leran 2 berbentuk mirip kuncup bunga (Gunadi, dkk. 2012, 28-45). Perbedaan itu antara lain, ukuran gigi manusia Leran lebih besar dan lebih panjang dibanding dengan gigi manusia Binangun, sehingga gigi manusia Leran 1 dan Leran 2 dapat dibentuk seperti terlihat pada foto 2 dan foto 3. Lebih jauh dijelaskan oleh Toetik Koesbardiati bahwa bentuk gigi seperti pada manusia Binangun ataupun Leran 1 dan Leran 2 di Indonesia masih jarang ditemukan. Bentuk gigi mirip mata gergaji sama dengan yang ditemukan di Situs Semawang, Bali (Koesbardiati \& Suriyanto 2007, 37-39). Sedangkan pada populasi manusia hidup modifikasi peruncingan gigi masih dapat ditemukan pada masyarakat Mentawai (http://www.en.wikipedia.org/wiki /Human tooth sharpening). Di tempat lain, bentuk gigi seperti pada manusia 
Leran 1 dan Leran 2 belum pernah ditemukan.

\section{MODIFIKASI GIGI: BUDAYA ATAU ALAMI}

Pada awalnya ilmu kedokteran gigi mempelajari hal-hal yang berkaitan dengan fungsi penting gigi bagi manusia yaitu pengunyahan, bicara, dan estetika. Selanjutnya berkembang untuk mencari

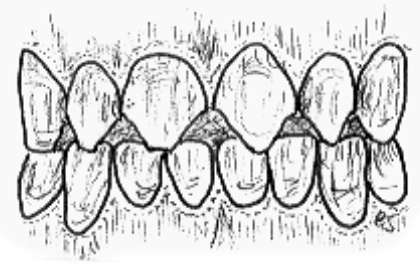

Gambar 1. Lubang di antara gigi akibat kebiasaan menggigit pipa rokok (Sumber: http://www.ddsintraining. com/the-cultural-modification-ofteeth/)

hubungan antara bentuk gigi dan perilaku seseorang baik kebiasaan sehari-hari yang dilakukan secara berkesinambungan dengan menggunakan gigi ataupun mencari tahu kira-kira jenis makanan yang banyak dikonsumsi oleh seseorang. Salah satu contoh seseorang yang memiliki kebiasaan menggigit benda keras seperti misalnya pipa rokok, maka akibatnya gigi bagian depan akan terkikis sedikit demi sedikit yang akhirnya akan membentuk lubang seperti terlihat pada gambar 1.

Dengan mempelajari bentuk gigi yang disebabkan dari perilaku seseorang, maka ilmu kedokteran gigi berkembang terkait dengan ilmu antropologi budaya. Dengan demikian, fungsi gigi dalam kajian selanjutnya dapat disejajarkan sebagai artefak yang dapat menjelaskan tentang perilaku manusia (Milner \& Larsen 1991). Bahkan di negara-negara maju dalam peneltian arkeologi khususnya pada situssitus kubur, mereka selalu melakukan analisis gigi-geligi dari rangka manusia yang ditemukan dalam penelitian tersebut.

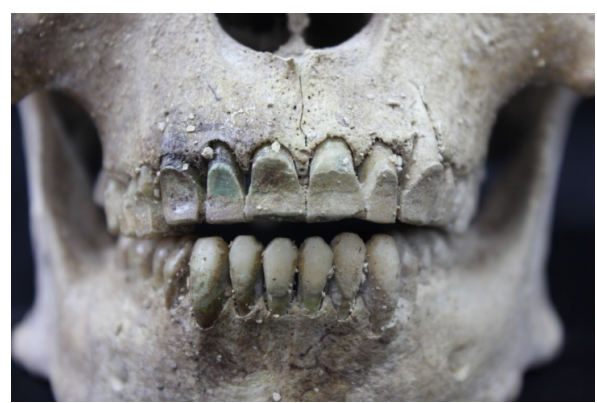

Foto 4. Peruncingan gigi seri rahang bawah (Dok. Toetik Koesbardiati).

archaeology ${ }^{7}$ belum banyak dilakukan, oleh karena itu dalam penelitian di Situs Leran dan Binangun mulai dibangun kembali penelitian arkeologi dengan melibatkan disiplin paleoantropologi. James George Frazer $^{8}$ sejak tahun 1930-an secara antropologis telah melakukan kajian tentang modifikasi gigi pada suku-suku tertentu, dan ini merupakan bagian dari penelitiannya tentang konsep totem di beberapa etnik di dunia. Secara historis memodifikasi bentuk gigi seperti yang dilakukan oleh masyarakat Bali dikarenakan adanya kepercayaan bahwa pada dasarnya gigi manusia merupakan representasi dari sifat marah, irihati dan sifat-sifat buruk lainnya (Frazer 1935, 187). Agar sifat-sifat buruk tersebut tidak masuk ke dalam jiwa seseorang, maka gigi orang itu harus dipotong sebagian dan direndahkan, sehingga gigi bagian depan tampak rata ${ }^{9}$.

Di tempat lain modifikasi gigi justru dibentuk dengan berbagai variasi, baik yang berlatar kepercayaan maupun yang bertujuan untuk fashion. Beberapa model bentuk modifikasi gigi dari situs-situs di

\footnotetext{
7 Dari analisis gigi dapat diketahui berbagai informasi sejarah seseorang, misalnya pola makan, jenis penyakit yang diderita, usia, dan modifikasi gigi (seperti dilakukan oleh Andrew Kenneth Scherer dalam disertasinya berjudul Dental Analysis of Classic Period Population Variability in The Maya Area).

James Frazer atau Sir James George Frazer, keturunan

Skotlandia lahir di Glasgow, Skotlandia 1 Januari 1854 dan wafat 7 Mei 1941 di Cambridge, UK. Beliau diakui sebagai pelopor Antropologi Modern.

9 Di Jawa dikenal dengan istilah pasah-pangur. Di Bali tradisi pangur hingga saat ini masih dilakukan oleh masyarakat Hindu Bali karena merupakan salah satu ritual dalam kehidupan mereka. Tradisi pangur di Jawa sudah punah kira-
} kira 40 - 50 tahun yang lalu. 
Mesoamerika telah diklasifikasi oleh Javier Romero Molina seorang peneliti antropologi fisik dari Universidad Nacional Autonoma de Mexico. Klasifikasi Romero inilah hingga kini menjadi acuan para peneliti modifikasi ataupun mutilasi gigi manusia (Williams \& White 2006, 139151). Adapun klasifikasi Romero seperti dikutip Williams dan White dapat dilihat pada lampiran nomor 1 di bawah.
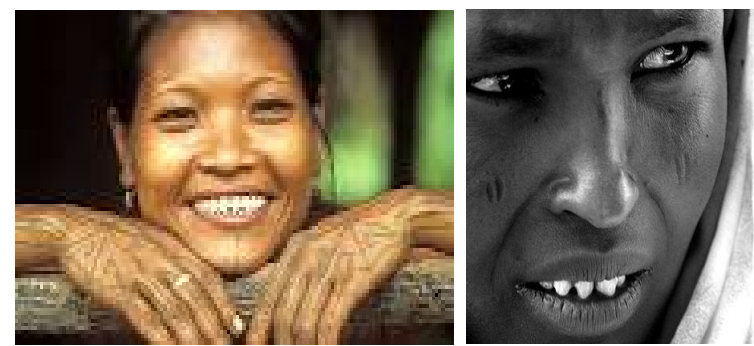

Foto 5. Wanita M entawai yang masih memperuncing gigi dan membuat tato di bagian tubuh mereka (Sumber: http:// www.en.wikipedia.org/wiki/Human tooth sharpening).

\section{PEMBAHASAN}

Dalam laporan hasil penelitian Situs Kubur Prasejarah di Pantai Utara Kabupaten Rembang, Jawa Tengah tahun 2012 berdasarkan analisis pertanggalan $\mathrm{C} 14$ diketahui bahwa umur Situs Leran yaitu $2640 \pm 160 \mathrm{BP}^{10}$ atau abad 5 Sebelum Masehi (Gunadi, dkk. 2012, 87). Walaupun pertanggalan secara absolut Situs Binangun belum diketahui, namun secara relatif dapat disejajarkan dengan umur Situs Leran. Dengan demikian, antara manusia Binangun dan manusia Leran diperkirakan berasal dari satu masa yang sama. Walaupun di antara keduanya memiliki perbedaan budaya dalam memodifikasi bentuk gigi.

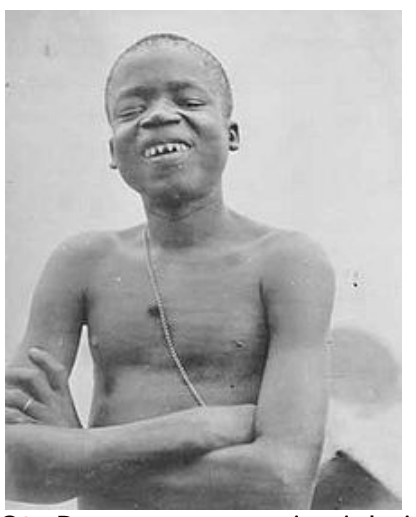

Foto 6. Ota Benga, seorang pigmi dari Kongo (Sumber: http://blog.bodycandy.com)

Modifikasi bentuk gigi meruncing seperti ditemukan pada gigi manusia Binangun dikatakan oleh Koesbardiati bahwa hal serupa juga dijumpai di Situs Semawang, Bali (periksa foto 4). Berbeda dengan manusia Binangun, peruncingan gigi individu Semawang dilakukan pada gigi rahang bawah, sementara gigi seri rahang atas kelihatan diratakan (dipangur). Budaya atau tradisi modifikasi bentuk gigi dijumpai di beberapa tempat

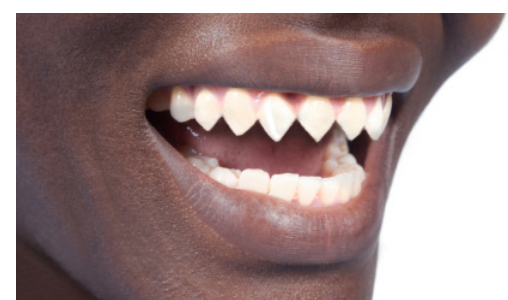

Foto 7. Contoh modifikasi gigi meruncing pada wanita Afrika (Sumber: http://blog.bodycandy.com)

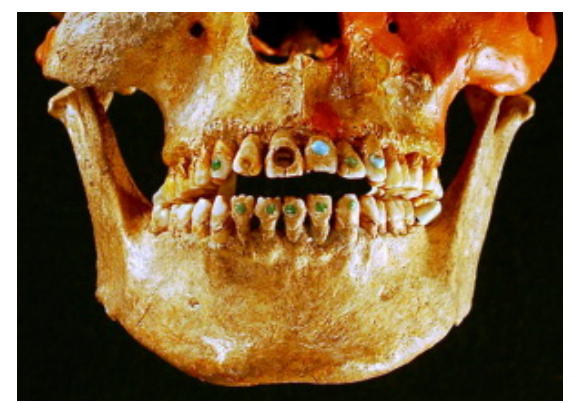

Foto 8. Modifikasi gigi suku Maya (Sumber: http://www.ddsintraining.com)

\footnotetext{
${ }^{10} \mathrm{BP}$ (Before Present) dengan patokan bahwa yang dimaksud waktu sekarang (present) adalah tahun 1950 yang lalu.
} 
di dunia antara lain Mesoamerika, Afrika, Asia, dan Asia Tenggara hingga Pasifik (Williams \& White 2006; Shah 2011; Domett, et.al. 2011; dan Lorn 2013).

Kebiasaan meruncingkan gigi sampai kini masih dilakukan oleh sebagian masyarakat Suku Mentawai di Sumatra Barat. Bagi mereka yang masih percaya dan taat akan ajaran leluhur sampai saat ini masih ada beberapa individu yang menajamkan gigi seri mereka. Namun, sebagian besar dari generasi muda Mentawai sudah tidak mau lagi melakukan hal seperti yang diajarkan oleh nenek moyang mereka. Terutama bagi mereka yang sudah mengenal pergaulan luas, mereka akan malu diejek oleh temanteman mereka. Tradisi meruncingkan gigi di Mentawai dapat dikatakan sudah akan punah. Bagi mereka budaya Mentawai yang menarik tidak hanya meruncingkan gigi akan tetapi masih banyak budaya yang menarik lainnya yang perlu dipertahankan (Anonim 2008).

Modifikasi dengan meruncingkan gigi ditemukan pula di Afrika terutama di Afrika Barat dan Kongo. Bagi orang-orang pigmi Afrika termasuk Suku Baka dan Suku Mbuti budaya meruncingkan gigi merupakan salah satu kegiatan ritual dalam siklus hidup manusia, yaitu sebagai tanda seseorang memasuki usia dewasa. Di alam modern budaya tersebut merupakan sesuatu yang aneh, sehingga pada awal tahun 1900-an salah seorang pigmi dari Kongo bernama Ota Benga yang memiliki gigi dengan modifikasi meruncing sengaja dibawa ke Amerika Serikat untuk mengisi pameran kebudayaan di beberapa kota di Amerika Serikat (Lorn 2013). Di Afrika tradisi meruncingkan gigi juga dilakukan oleh para wanita seperti halnya masyarakat Mentawai, Sumatra Barat. Budaya atau tradisi meruncingkan gigi pada rahang atas seperti yang ditemukan pada manusia Binangun adalah sisa-sisa tradisi kuno yang apabila merujuk ke tradisi Suku Maya di Mesoamerika tradisi modifikasi gigi telah ada sejak 1400 Sebelum Masehi. Tentang kapan modifikasi gigi

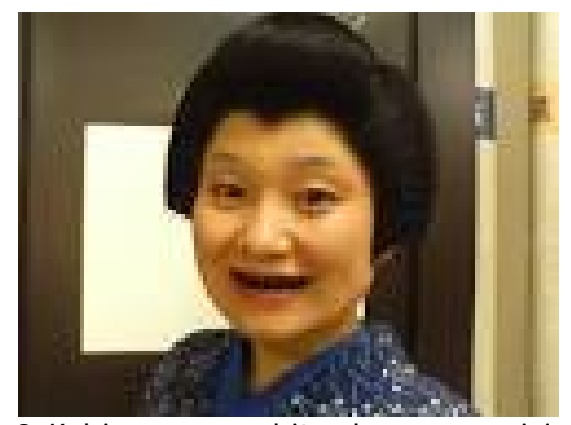

Foto 9. Kebiasaan menghitamkan warna gigi pada wanita Jepang

(Sumber: http://en.wikipedia.org/wiki/Ohaquro).

mulai dikenal di daerah Mesoamerika dikuatkan dari hasil penelitian GabanyGuerrero dari University of Connecticut menyatakan bahwa berdasarkan analisis temuan gigi dari situs di Meksiko Tengah, Mesoamerika ditemukan umur antara 2570 - 2322 BC (Roach 2006).

Bentuk modifikasi gigi yang oleh Toetik Koesbardiati dikatakan mirip kuncup bunga, selain gambar dari klasifikasi Romero (terlampir), sampai saat ini penulis belum menemukan contoh lainnya. Berdasarkan klasifikasi Romero (Romero's system of classification for teeth with dental modification), bentuk modifikasi tersebut termasuk tipe C3, sedangkan bentuk meruncing seperti pada gigi manusia Binangun masuk dalam klasifikasi tipe C5 (Williams \& White 2006 140 dan periksa lampiran 1). Foto 8 di atas salah satu contoh tipe lain dari klasifikasi Romero, terlihat bahwa pada satu individu memiliki modifikasi gigi lebih dari satu tipe. Pada foto 8 tampak bahwa pada gigi seri rahang atas modifikasi gigi tipe $E 1$, sedangkan empat gigi seri rahang bawah dapat diklasifikasikan pada tipe G11.

Budaya atau tradisi modifikasi gigi tidak harus merubah bentuk gigi. Di beberapa suku bangsa, modifikasi gigi cukup dengan membuat warna gigi menjadi gelap. Di Jepang misalnya ada tradisi yang dikenal dengan Ohaguro ${ }^{11}$

\footnotetext{
${ }^{11}$ Kebiasaan menghitamkan gigi sangat popular di kalangan kaum wanita Jepang hingga era kekaisaran Meiji yaitu antara tahun 1868 - 1912 (http://en.wikipedia.org/wiki/Meiji_period)
} 
atau Japanese Teeth Blackening yaitu tradisi menghitamkan gigi seseorang dengan menggunakan cairan warna hitam yang dioleskan pada permukaan gigi. Kebiasaan menghitamkan gigi dilakukan pula oleh masyarakat di Vietnam, Laos, Thailand dan Asia Tenggara pada umumnya. Selain merupakan salah satu perilaku keagamaan, budaya menghitamkan gigi dengan makan sirihpinang setiap saat dan setiap hari seperti yang dilakukan penduduk di AsiaTenggara dan Pasifik. Mereka juga percaya bahwa warna hitam akibat kebiasaan makan sirih-pinang akan menyehatkan gigi. Oleh karena itu, tidak mengherankan apabila kebiasaan makan sirih pinang yang dicampur dengan sedikit kapur hingga sekarang masih dilakukan oleh orang-orang di Asia Tenggara dan Pasifik (Rooney 1995), termasuk beberapa etnis di Indonesia.

\section{PENUTUP}

Berdasarkan kajian tentang modifikasi gigi seperti yang ditemukan di situs-situs lain, seperti di Semawang, Bali dan di Meso-Amerika, serta living tradition seperti ditemukan di Mentawai, Sumatera Barat dan di Afrika, maka dapat disimpulkan bahwa bentuk gigi seperti yang dimiliki individu dari Situs Binangun dan Situs Leran merupakan modifikasi gigi yang dilakukan secara sengaja karena pertimbangan kepercayaan atau religi. Dengan kata lain dapat disimpulkan bahwa individu manusia Binangun dan manusia Leran telah mengenal modifikasi bentuk gigi seperti yang dilakukan oleh manusia dari benua lain misalnya Amerika dan Afrika. Modifikasi gigi tidak harus dengan mutilasi, melainkan adapula dengan cara implantasi yaitu menambahkan sesuatu material pada gigi.

Selanjutnya, modifikasi gigi dengan menghitamkan warna gigi rupa-rupanya didominasi oleh masyarakat penutur rumpun bahasa Austronesia baik yang berada di Jepang, Asia Tenggara hingga Pasifik. Sedangkan modifikasi gigi seperti yang dilakukan oleh manusia Binangun dan Leran sama dengan kebiasaan yang dilakukan oleh suku Mentawai di Sumatera Barat. Adapun secara artefaktual modifikasi gigi dengan meruncingkan gigi seri, di Indonesia ditemukan di Situs Semawang, Bali dan Situs Binangun, Kabupaten Rembang. Seperti telah dijelaskan di atas bahwa modifikasi gigi di Asia Tenggara dan Pasifik cenderung dengan menghitamkan gigi. Walaupun ada data yang ditemukan di Situs Semawang, Bali dan juga Living Tradition seperti yang dilakukan orang Mentawai, Sumatra Barat. Dengan demikian dapat disimpulkan bahwa modifikasi gigi yang dilakukan oleh masyarakat atau etnis tertentu di belahan dunia ini, baik dengan cara mutilasi ataupun implantasi misalnya memberi warna (bahkan ada yang menambahkan materi seperti terlihat pada foto 8) adalah hasil budaya manusia.

Budaya modifikasi gigi baik dengan cara mutilasi ataupun implantasi ruparupanya telah berlangsung sejak masa prasejarah dan berlanjut hingga sekarang. Modifikasi gigi dengan cara mutilasi seperti dilakukan manusia Binangun dan manusia Leran, sisa-sisa budaya tersebut hingga abad 20 masih ditemukan baik di Indonesia maupun di tempat lain seperti di Afrika. Kebiasaan makan pinang sirih yang dilakukan oleh masyarakat penutur rumpun bahasa Austronesia yang tersebar di Asia Tenggara dan Pasifik, salah satu bukti lain tentang budaya modifikasi gigi. Bahkan budaya modifikasi gigi dengan cara implantasi seperti terlihat pada foto 9 , memasang berlian pada gigi, sejak tahun 2012-2013 menjadi tren terutama di kalangan selebriti.

Penelitian Situs Kubur Prasejarah di Pantai Utara Kabupaten Rembang, Jawa Tengah masih menyisakan berbagai pertanyaan penelitian (research questions) yang menantang. Oleh karena itu, penelitian-penelitian lanjutan masih perlu dilakukan terutama penelitian yang bersifat kolaboratif yang melibatkan berbagai disiplin antara lain Paleoantropologi, Geologi dan Biologi. Dengan model 
penelitian yang kolaboratif, diharapkan kelemahan kajian Bio-archaeology, Osteoarchaeology, maupun Geo-archaeology dalam penelitian arkeologi dapat dibangun kembali, sehingga akan diperoleh hasil yang komprehensif.

Munculnya beberapa pertanyaan penelitian pada bagian kesimpulan, merekomendasikan perlu dilakukan penelitian lanjutan dengan cakupan situs yang lebih luas. Selain mencari data baru, baik yang bersifat kuantitatif maupun kualitatif, diharapkan penelitian-penelitian berikutnya akan diperoleh data permukiman selain situs kubur. Pola permukiman masyarakat Austronesia di pantai utara Jawa Tengah, setting perkampungan mereka, perlu diketahui dan diungkap karena antara aktivitas penguburan tidak dapat dipisahkan dari pola penghidupan, termasuk di dalamnya adalah pola permukimannya. Oleh karena itu perlu penelitian yang berkesinambungan.

\section{UCAPAN TERIMA KASIH}

Pada kesempatan ini ijinkan saya mengucapkan terima kasih kepada Prof. Dr. Sumijati Atmosudiro, Dr. Toetik Koesbardiati, Dr. Goenadi Nitihaminoto, Agus Tri Hascaryo, SS, ST, MSi. Sofwan Noerwidi, SS., MSc., Bayu Delta Murti, M.Hum. Hadi Sunaryo, Z. Dekon Suyanto, dan semua anggota Tim Penelitian atas kerjasamanya sehingga penelitian dapat berjalan dengan sukses. 


\section{DAFTAR PUSTAKA}

Anonim, 2008. "Sharpening Teeth Competition, Elegance Mentawai Tribe", http://globalwashlap.blogspot.com, dimuat pada hari Minggu, 28 December 2008.

Bellwood, Peter. 2000. Prasejarah Kepulauan Indo-Malaysia (Edisi Revisi). Jakarta: PT. Gramedia Pustaka Utama.

Domett, K.M., et.al. 2011. "Cultural Modification of the Dentition in Prehistoric Cambodia" dalam International Journal of Osteoarchaeology. Published online in Wiley Online Library.

Frazer, J. G. 1935. Totemism and Exogamy: A Treatise on Certain Early Forms of Superstition and Society. London: Macmillan and Co Limited.

Gunadi, dkk. 2012. "Penelitian Situs Kubur Prasejarah Di Pantai Utara Kabupaten Rembang, Jawa Tengah". Laporan Penelitian Arkeologi. Balai Arkeologi Yogyakarta. Tidak Diterbitkan.

2013. "Penelitian Kubur Prasejarah di Situs Leran, Kecamatan Sluke, Kabupaten Rembang, Propinsi Jawa Tengah". Laporan Penelitian Arkeologi. Balai Arkeologi Yogyakarta. Tidak Diterbitkan.

Heekeren, H.R. van 1972. "The Stone Age of Indonesia". Verhandelingen van het Koninklijk Instituut voor Tall Land en Volkenkunde Vol. 61. The Hague: Martinus Nijhoff.

Kasnowihardjo, Gunadi. 2013. "Temuan Rangka Manusia di Pantura Jawa Tengah: Sebuah Kajian Awal" dalam Jurnal Berkala Arkeologi, Vol. 33 No. 1 - Mei 2013. Yogyakarta: Balai Arkeologi Yogyakarta. HIm. 1-12.

Koesbardiati, Toetik dan Rusyad Adi Suriyanto. 2007. "Menelusuri Jejak Populasi Morfologi Pangur Gigi-Geligi: Kajian Pendahuluan atas Sampel Gigi-Geligi dari Beberapa Situs Purbakala di Jawa, Bali, dan Nusa Tenggara Timur" dalam HUMANIORA, Vol. 19, No. 1 - Februari 2007. Yogyakarta: Fakulatas IImu Budaya Universitas Gadjah Mada. HIm. 33-42.

Lorn, 2013. "Modification Around the World: Tooth Filing in Africa". (http://blog.bodycandy.com /2012/07/27/modification-around-the-world-tooth-filing-inafrica/)

Masinambow, E.K.M., dkk. 2004. "Masyarakat Austronesia: Fakta atau Fiksi?" dalam Polemik tentang Masyarakat Austronesia. Jakarta: Lembaga IImu Pengetahuan Indonesia Direktorat Jenderal Pendidikan Tinggi, Departemen Pendidikan Nasional. HIm. 1-9.

Milner, G. and C. Larsen. 1991. "Teeth As Artifacts of Human Behavior: Intentional Mutilation and Accidental Modification" dalam Advances in Dental Anthropology. New York: Willey-Liss.

Roach, John. 2006. "Oldest Dentistry in Americas". National Geographic News. Tayang Kamis, 28 October 2010. 
Rooney, Dawn. F. 1995. "Betel Chewing in South-East Asia". Artikel disampaikan dalam the Centre National de la Recherche Scientifique (CNRS) di Lyon, France, Agustus 1995.

Shah, 2011. "Tooth Modification in Asia and Africa". (http://Openlab.citytech.cuny.edu/resd1110 fall2011/2011/11/01/abstract-assignment/)

Soegondho, Santoso, 1995. Tradisi Gerabah di Indonesia, Dari Masa Prasejarah Hingga Masa Kini. Jakarta: Himpunan Keramik Indonesia,.

Soejono, R.P. dan R.Z. Leirissa (ed). 2008. Sejarah Nasional Indonesia I (Edisi Pemutakhiran). Jakarta: Balai Pustaka.

Sukendar, Haris dan Rokhus Due Awe. 1981. "Laporan Penelitian Terjan dan Plawangan Jawa Tengah". Berita Penelitian Arkeologi No. 27. Proyek Penelitian Purbakala Jakarta, Departemen P \& K.

William, Jocelyn. S dan Christine D White. 2006. "Dental Modification in the Postclassic Population From Lamanai, Belize" dalam Ancient Mesoamerica, Vol. 17. Cambridge University Press. HIm. 139-151.

http://en.wikipedia.org/wiki/Ohaguro

http://en.wikipedia.org/wiki/Meiji period

www.blog.bodycandy.com

www.ddsintraining.com 


\section{Lampiran 1.}

Klasifikasi Modifikasi Gigi Oleh Romero

$$
\text { A } \mathrm{A}^{2} \mathrm{~A}^{3} \mathrm{~B}^{4} \mathrm{H}^{5}
$$

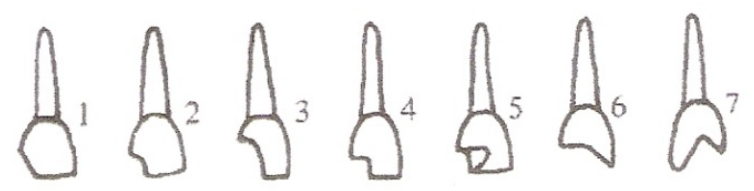

c

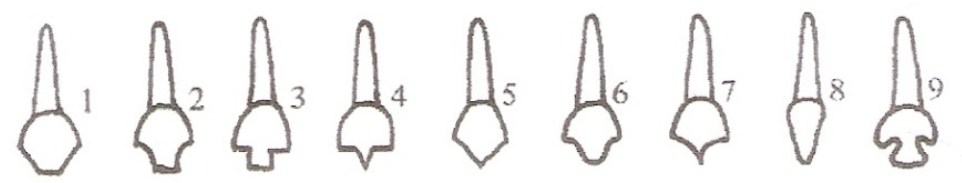

D

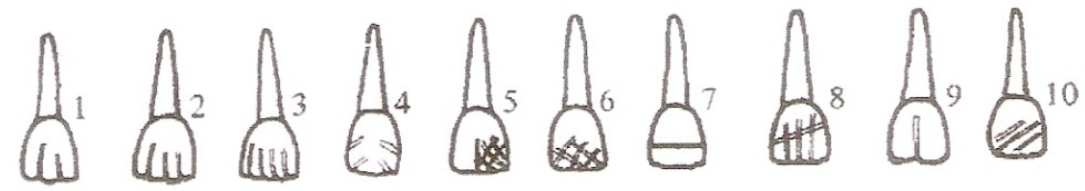

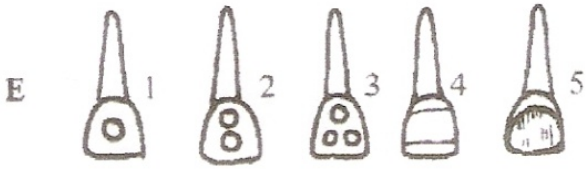

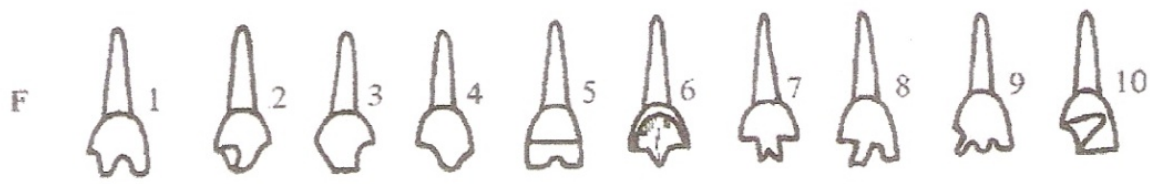<smiles>C1CC2CC3CC(C3)C(C1)C2</smiles>

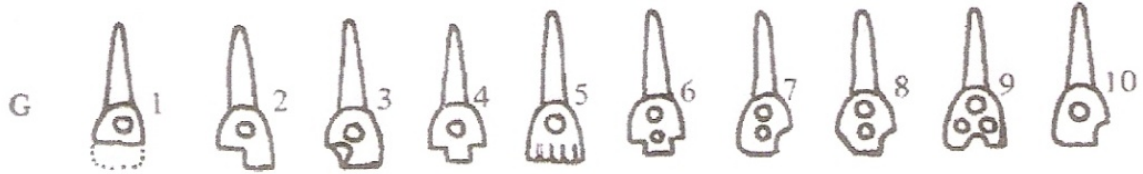

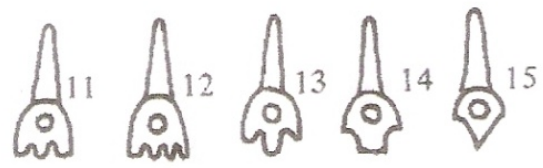

Sumber : William \& White, 2006, 140. 


\section{Lampiran 2.}

Gambar Temuan Rangka di Situs Kubur Prasejarah Leran

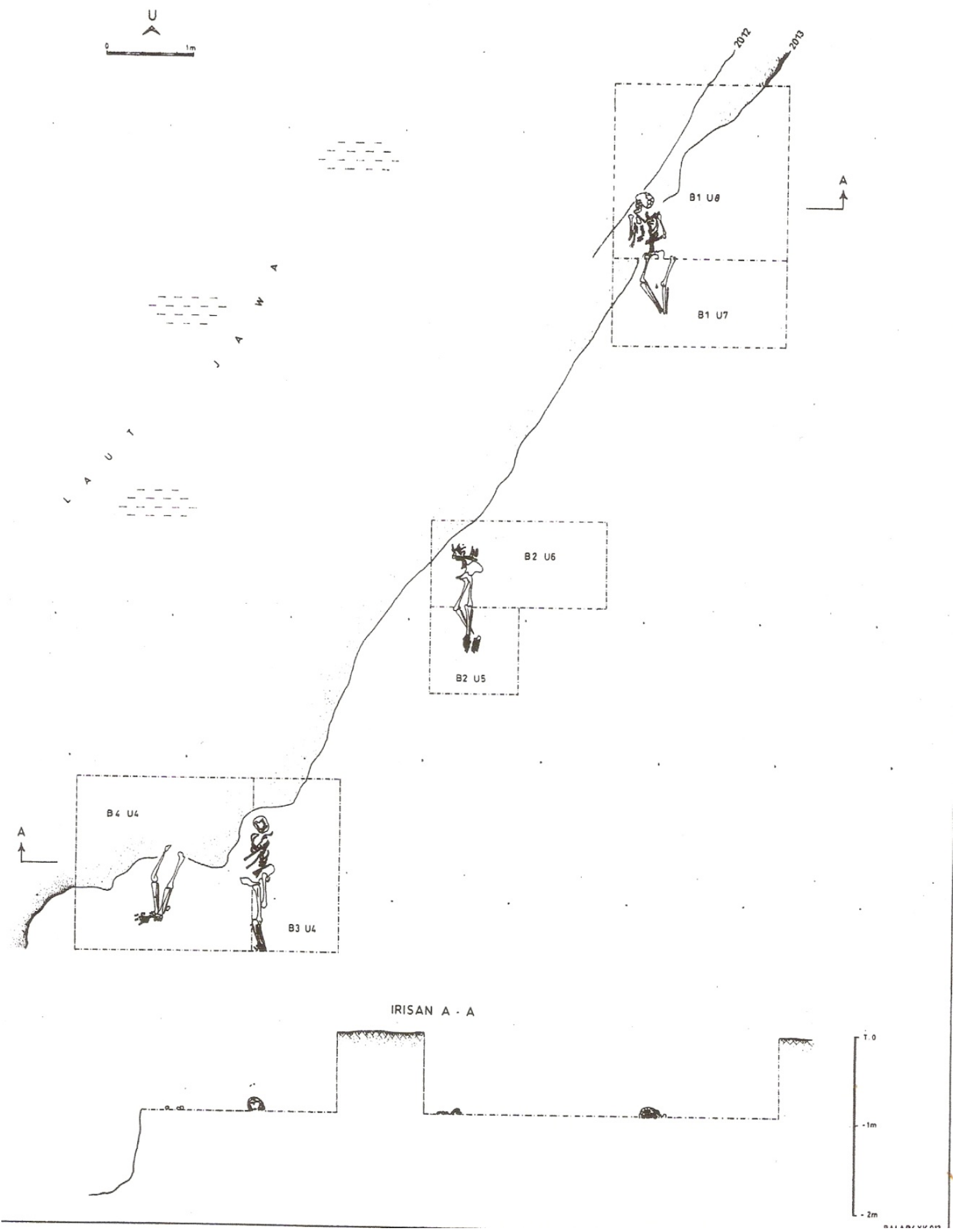

Dok. Balar Yogyakarta 


\section{Lampiran 3.}

Peta Situs Leran

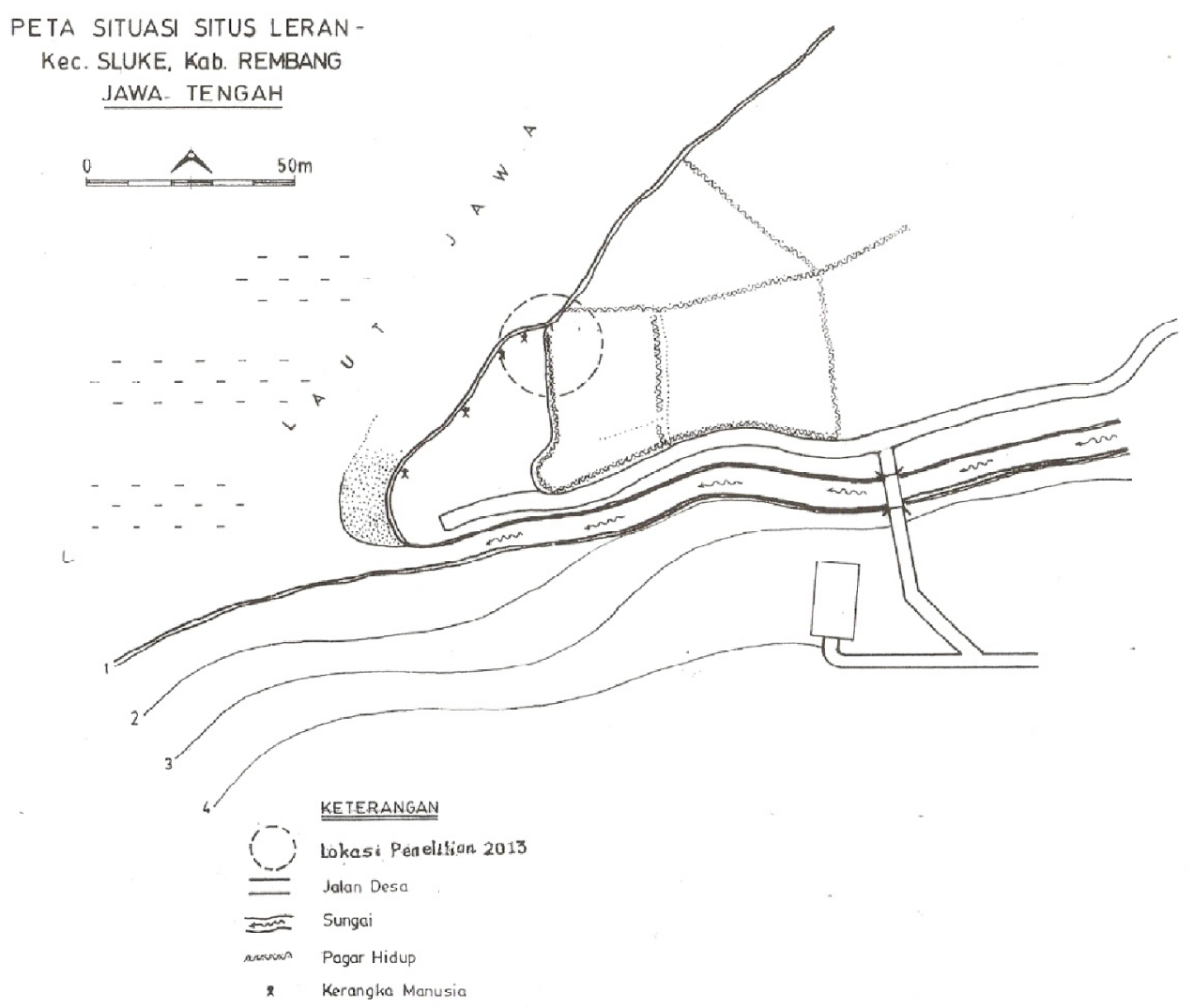

Dok. Balar Yogyakarta 
